\title{
Mário de Andrade e Aloísio Magalhães: Dois personagens e a questão do patrimônio cultural brasileiro
}

\author{
Marcelo de Brito Albuquerque \\ Pontes Freitas
}

Aluno de doutorado - FAUUSP

O artigo mostra como foi construída a noção de patrimônio cultural Resumo no Brasil, tomando por referência o pensamento de dois intelectuais que, em momentos distintos, estiveram engajados na política de preservação deste patrimônio: Mário de Andrade e Aloísio Magalhães.

Para isto, observa-se suas trajetórias institucionais junto aos aparelhos de Estado responsáveis pela preservação do patrimônio cultural brasileiro, identificando, a partir da análise de documentos, as formas de articulação de seus pensamentos com o processo de constituição deste patrimônio e, conseqüentemente, da memória nacional.

The article shows the development of the concept of cultural Abstract heritage in Brazil according with the thought of two important intelectuals who, in different moments, were engaged in preservation policies: Mário de Andrade and Aloísio Magalhães. The development of two public institutions responsible for that preservation is analized as well the ways in which their thoughts influenced the concept of cultural heritage and national memory. 
(1) Programa interministerial, criado em 1973, composto pelos ministérios do Planejamento e Coordenação geral (MINIPLAN), da Educação e Cultura (MEC), do Interior (MINTER) e da Indústria e Comércio (MIC)

(2) O CNRC, como um grupo de trabalho coordenado por Aloísio Magalhães, com o apoio do ministro da Indústria e Comércio Severo Gomes, surgiu em 1975. Ele fo constituído em decorrência à assinatura de um convênio entre o MIC e o governo do Distrito Federal. Com este convênio buscou-se viabilizar a implantação do projeto 01.01 .75 do MIC/STI.

(3) Em 1979, a liderança do CNRC Aloísio Magalhães assumiu a direção do IPHAN, nomeado pelo ministro da Educação e Cultura Eduardo Portella, endo O IPHAN absorvido o CNRC e o $\mathrm{PCH}$. Pouco depois, foi criada a Secretaria do Patrimônio Histórico

Artístico Nacional (SPHAN), po transformaçāo do IPHAN, através do Decreto n. 84.198, e foi aprovada pelo Congresso Nacional a Lei n. 6.757 que autorizava o poder executivo instituir a Fundação Nacional Pró Memória (Pró-Memória ou FNPM), entidade incumbida de executar a política da SPHAN. A Pró-Memória incorporou o $\mathrm{PCH}$, o CNRC e um pequeno grupo da Secretaria de Modernização e Reforma Administrativa do Ministério do Planejamento (SEMOR), que trabalhava na área de modernizaçāo do sistema de preservação. Aloísio Magalhāes assumiu a direçāo da SPHAN e da Pró-Memória.
Na década de 70, a política de preservação do patrimônio cultural no Brasil passou por sucessivas transformações, seja em sua forma de gestão, como também nas concepções teórico-metodológicas nela aplicadas. Desde a fundação do Serviço do Patrimônio Histórico e Artístico Nacional (SPHAN), em 1937, até o final dos anos 60 , tivemos um modelo de política centralizado, fundamentado na noção de patrimônio histórico e artístico e numa prática de preservação baseada na metodologia do restauro e da conservação do patrimônio arquitetônico. Além disso, esta prática era guiada pela noção de monumentalidade que estava associada aos valores históricos e artísticos.

Com o advento, nos anos 70 , das experiências do Programa de Cidades Históricas (PCH) ${ }^{1}$ e do Centro Nacional de Referência Cultural $(\mathrm{CNRC})^{2}$, construídos externamente à estrutura do então Instituto do Patrimônio Histórico e Artístico Nacional (IPHAN), houve uma significativa transformação nesta conjuntura. $\mathrm{O} P C H$ aprofundou o movimento, já em andamento, de descentralização administrativa nesta área, significando também um aumento dos recursos humanos e financeiros nela aplicados. Por outro lado, o CNRC representou, sobretudo, uma renovação conceituai na esfera patrimonial da política de cultura desenvolvida pelo Estado. Esta renovação se estendeu aos anos 80 , quando sua liderança foi alçada à condução do SPHAN/Pró-Memória ${ }^{3}$ e teve seu conteúdo definitivamente materializado na Constituição Federal de 1988, ao se definir, em seu artigo 216, que:

"Constituem patrimônio cultural brasileiro os bens de natureza material e imaterial, tomados individualmente ou em conjunto, portadores de referência à identidade, à ação, à memória dos diferentes grupos formadores da sociedade brasileira, nos quais se incluem:

1 - as formas de expressão;

11 - os modos de criar, fazer e viver;

III - as criações científicas, artísticas e tecnológicas;

IV - as obras, objetos, documentos, edificações e demais espaços destinados às manifestações artístico-culturais;

$V$ - os conjuntos urbanos e sítios de valor histórico, paisagístico, artístico, arqueológico, paleontológico, ecológico e científico."

Segundo nosso ponto de vista foram dois os intelectuais que, em momentos distintos, com suas trajetórias na política de preservação 
do patrimônio cultural do país, deram uma valiosa contribuição à definição desta noção ampliada de patrimônio cultural. Foram eles: Mário de Andrade e Aloísio Magalhães.

No pensamento de Mário de Andrade nota-se uma ênfase nos aspectos artísticos do patrimônio cultural. Ele não vinculou diretamente a questão da cultura nacional a um modelo de desenvolvimento econômico e social, o que, por outro lado, Aloísio Magalhães fez. Este vinculou a questão da cultura nacional a um modelo, a um projeto de desenvolvimento. Aloísio Magalhães pensou colar o projeto de desenvolvimento socioeconômico do país a outro de desenvolvimento cultural. Por isso a sua busca de qualificação dos referenciais culturais próprios, sobretudo, a partir do estudo de atividades artesanais ou pré-industriais tradicionais. Ele, em sua política cultural e patrimonial, destacou a dimensão da distribuição e do consumo dos bens culturais em lugar da exclusiva visão da preservação. Visão hegemônica na trajetória institucional do SPHAN, onde se sobrepunha o interesse pelo restauro e conservação dos monumentos arquitetônicos.

Neste sentido, o objetivo deste texto é determinar o papel que cada um deles, enquanto organizadores e difusores de uma concepção de cultura, diversa e pluralista, desempenhou neste processo.

Para tanto, buscaremos observar suas atividades intelectuais e institucionais, privilegiando em alguns momentos a análise dos mecanismos discursivos que tornaram possível a definição da política de preservação do patrimônio cultural do país e a constituição deste patrimônio.

A estrutura do trabalho está definida em três partes. A primeira consiste na apresentação da trajetória intelectual e institucional de Mário de Andrade, dos anos 20 até a década de 40. Ver-se-á como, através de sua preocupação inicial de formação de uma produção artística genuinamente nacional, Mário de Andrade enveredou por suas ações de identificação e preservação do patrimônio cultural brasileiro (viagens etnográficas, Departamento de Cultura do Município de São Paulo, SPHAN, etc.). Em seguida, será traçada a trajetória de Aloísio Magalhães no CNRC e no SPHAN/Pró-Memória. Serão observadas suas preocupações quanto à necessidade de se fundamentar o modelo de desenvolvimento socioeconômico do país em referenciais 
culturais próprios, nacionais. O mapeamento destes referenciais culturais e a necessidade de sua dinamização e devolução à nação levará Aloísio Magalhães a voltar-se para a área patrimonial. Neste momento serão encontradas as causas de referência do pensamento de Mário de Andrade em Aloísio Magalhães. Por último, será demonstrada como os ideários de Mário de Andrade e Aloísio Magalhães são a base desta noção ampliada de patrimônio cultural presente na Constituição de 1988. Além disso, observar-se-á a perspectiva que a adoção desta noção abre para o exercício da política de presevação do patrimônio cultural do país.

\section{Mário de Andrade e a noção de patrimônio artístico nacional}

Para se entender como Mário de Andrade estruturou sua concepção de patrimônio artístico deve-se, antes de tudo, observar como se constituiu a idéia de modernidade no modernismo brasileiro. Neste sentido, inicialmente, examinar-se-ão três questões que estão diretamente vinculadas ao processo de modernização cultural levado à frente pelos intelectuais modernistas na década de 20 , a saber: 1 - a atualização e renovação da esfera da produção artística; 2 - a defesa da nacionalização dos temas desta produção, e; 3 - o compromisso com a tradição.

A eclosão do tema da modernidade em nosso ambiente cultural é marcada pela preocupação quanto à necessidade de renovação e de atualização da produção artística brasileira, de forma a que ela se situasse no patamar da produção internacional. O esforço de produção de uma linguagem artística adequada à modernidade, isto é, a um tipo de experiência vital resultante da sociedade industrial e urbana ${ }^{4}$, foi, entretanto, vislumbrado segundo parâmetros diversos nos anos 20 .

Segundo Moraes (1988), o movimento modernista brasileiro nos anos 20 foi constituído em dois tempos. No primeiro, o acesso à modernidade era visto sob o prisma do imediatismo. Nesta concepção não era apreciada a posição do país no cenário internacional, sua condição de país subdesenvolvido, predominantemente agrário e rural, onde era ainda incipiente o processo de industrialização e urbanização.

Desta forma, "para viabilizar o processo de adequação da representação à realidade nova, os modernistas dos primeiros anos vão buscar nas tendências inovadoras européias os 
instrumentos que thes possibilitem efetuar a atualização da produção nacional. Neste período em que o panorama da vida urbana é aquilo que deve passar na estética nova (...) a incorporação na modernidade, integração do país no plano mundial, se faz pela absorção dos meios expressivos novos, importados, e pelo seu uso intensivo e polêmico na disputa com o passadismo." (Id., ibid., p. 227)

No entanto a partir de 1924, passou-se a adotar uma nova postura quanto a via de acesso da produção artística nacional à modernidade. Neste segundo tempo, o debate sobre as mediações que irão assegurar este acesso ganha novos contornos. Surge a idéia da mediação pela brasilidade. O que importa neste momento é mapear os temas nacionais que fundamentariam o acesso à modernidade. A brasilidade moldou desde então a concepção de modernidade no movimento modernista.

Dentro desta perspectiva, a idéia de modernidade foi associada à idéia de nacionalidade, pois o moderno passou a ser apresentado como nacional. Assim, a vocação universalista do movimento, acoplada à idéia de modernidade, não se antagonizou com a via nacionalista então adotada.

Neste segundo tempo é que foram realçados os vínculos entre a modernidade e a tradição, entre o novo e o antigo. Foi no passado cultural do país que se buscou parte das fontes da brasilidade. Mário de Andrade foi um dos integrantes deste processo, dando uma valiosa contribuição à identificação e à preservação dos bens culturais que constituíam a base da memória nacional.

O sentido de sua obra literária e político-cultural é modernizante e universalista. E dentro de sua busca de integração do país à modernidade, ele não hesita em utilizar o conceito de nacionalismo que está presente, como vimos, no segundo tempo modernista. Isto está bem claro, por exemplo, em sua correspondência com Carlos Drummond de Andrade. Em uma de suas cartas Mário afirma:

"Mais adiante você fala em 'apertado dilema: nacionalismo ou universalismo. O nacionalismo convém às massas, o universalismo convém às elites'. Tudo errado. Primeiro: não existe essa oposição entre nacionalismo e universalismo. O que há é mau 
nacionalismo: o Brasil pros-brasileiros - ou regionalismo exótico. Nacionalismo quer simplesmente dizer: ser nacional. O que mais simplesmente ainda significa ser. Ninguém que seja verdadeiramente, isto é, viva, se relacione com o seu passado, com as suas necessidades imediatas práticas e espirituais, se relacione com o meio e com a terra, com a família, etc., ninguém que seja verdadeiramente, deixará de ser nacional. É preciso começar esse trabalho de abrasileiramento do Brasil, dizia eu noutra carta, a um rapaz de Pernambuco. E agora reflita bem no que eu cantei no final do 'noturno' e você compreenderá a grandeza desse nacionalismo universalista que eu prego. De que maneira nós podemos concorrer pra grandeza da humanidade? É sendo franceses ou alemães? Não, porque isso já está na civilização. $O$ nosso contingente tem de ser brasileiro. $O$ dia em que nós formos inteiramente brasileiros e só brasileiros a humanidade estará rica de mais uma raça, rica duma nova combinação de qualidades humanas. (...). Nós imitando ou repetindo a civilização francesa, ou a alemã, somos uns primitivos, porque estamos ainda na fase do mimetismo. Nossos ideais não podem ser os da França porque as nossas necessidades são inteiramente outras, nosso povo outro, nossa terra outra, etc. Nós só seremos civilizados em relação às civilizações o dia em que criarmos o ideal, a orientação brasileira. Então passaremos da fase do mimetismo pra fase da criação. E então seremos universais, porque nacionais." (Andrade, 1988, p. 30-31).

Desta forma, o conceito de nacionalismo empregado por Mário de Andrade não representa uma negação ao ideal universalista que está associado ao modernismo. Pelo contrário, quando ele defende uma orientação brasileira à produção artística nacional o que ele busca alcançar em última instância é a integração do país no curso geral da modernidade. $O$ que devemos ter em conta, como bem afirma Moraes (1988, p. 234), é que "a preocupação de Mário de Andrade com sua proposta nacionalista diz respeito à problemática cultural dos países emergentes, países novos, e não às situações culturais já sedimentadas como nos países adiantados"

A incorporação à modernidade traduziu-se para Mário de Andrade na afirmação da identidade nacional do país. Para tanto era necessário que fossem identificados e recuperados os elementos distintivos da brasilidade, pois estes constituiam o fundamento desta identidade. $\mathrm{O}$ estudo destes elementos é uma constante 
na vida de Mário de Andrade. Já em 1917, ele viajou ao estado de Minas Gerais, entrando em contato com a arquitetura, pintura e escultura coloniais, em destaque a obra do Aleijadinho. A partir de suas observações locais, ele desenvolveu uma reavaliação crítica da arte colonial mineira, baseada em conhecimentos estéticos e históricos. Um dos resultados destas atividades foi a publicação em 1920 do ensaio "Arte religiosa no Brasil em Minas Gerais" na Revista do Brasil. Continuando seus estudos, Mário de Andrade voltou em 1924 a Minas Gerais, como integrante da Caravana Paulista ${ }^{5}$, tendo entrado em contato com o grupo modernista mineiro.

O conhecimento da arte barroca, ocorrido em paralelo ao encontro do grupo modernista paulista com o mineiro, representou um reforço ao movimento de revalorização e de divulgação desta arte enquanto um dos traços distintivos da cultura brasileira, tanto regional como nacional.

No final dos anos 20, Mário de Andrade continuou seu trabalho de mapeamento da cultura nacional por meio de suas "viagens etnográficas" ao Norte-Nordeste. Em 1927 ele conheceu a Amazônia. De dezembro de 1928 a fevereiro de 1929 ele visitou o Nordeste. Em ambas as viagens ele pesquisou e colheu dados sobre os usos, costumes, cantos e danças populares.

Ao desenvolver estas tarefas de mapeamento dos bens culturais, Mário de Andrade buscou dar substância àquela idéia de brasilidade contida nos anos 20. Neste contexto, ele ocupou claramente a posição de mediador entre a realidade socioeconômica do país e a construção de sua identidade e memória nacional.

Esta questão da brasilidade, de mapeamento dos bens culturais que possuem a propriedade distintiva do Brasil, é um dos pontos em torno dos quais girou a ação do Departamento de Cultura do Município de São Paulo (DC de São Paulo) durante a gestão Mário de Andrade ${ }^{6}$ Lá ele utilizou as técnicas de pesquisa sociológica e etnográfica, recém-introduzidas em São Paulo, buscando dar um grau científico a este projeto de mapeamento.

A Sociedade de Etnografia e Folclore de São Paulo ${ }^{7}$, fundada em dezembro de 1936, foi um dos principais agentes deste processo de cientificização do projeto de mapeamento da cultura nacional desenvolvido pelo DC de São Paulo. As atividades das
(5) Os outros integrantes da Caravana Paulista foram Olívia Guedes Penteado, Godofredo Teles, Tarsila do Amaral, Oswald de Andrade, pai e filho, e Blaise Cendrars.

(6) Mário de Andrade dirigiu o DC de Sāo Paulo e chefiou sua Divisão de Expansāo Cultural de 1935 a 1937.

(7) A Sociedade de Etnografia e Folclore teve como principais idealizadores Mário de Andrade, Claude e Dina Lévi-Strauss. Dentre os objetivos desta instituiçāo poderiamos destacar a realizaçāo de pesquisas de natureza folclórica e etnográfica e a proteçāo, conservaçāo e preservação dos documentos ou manifestaçōes de caráter etnográfico ou folclórico. Sobre a atuação da Sociedade de Etnografia e Folclore ver Soares (1983). 
duas instituições sempre estiveram muito vinculadas. A Missão de Pesquisas Folclóricas que o DC de São Paulo enviou ao Nordeste em 1938, por exemplo, foi o resultado prático de um curso de etnografia da sociedade, iniciado em 1936, que foi ministrado por Dina Lévi-Strauss. A missão foi a continuação de certa forma das viagens etnográficas realizadas por Mário de Andrade ao final dos anos 20. Através da missão, que foi chefiada por Luís Saia, o DC procedeu a gravação e a filmagem de músicas, danças, costumes e cultos afro-brasileiros no Nordeste.

Esta preocupação com o mapeamento da cultura nacional, presente no pensamento de Mário de Andrade, está também associado a uma outra que se refere à democratização cultural. Neste sentido, suas atividades no DC de São Paulo sinalizavam um claro propósito de implementar uma aproximação da arte erudita à popular. Por um lado, Mário se bate pela necessidade de valorização e divulgação da arte popular. Por outro, pela necessidade de acessibilidade da arte erudita a amplas camadas da população. Mário de Andrade firmou no DC de São Paulo uma linha de atuação pluralista voltada para atividades de pesquisa, de divulgação e de fruição dos bens culturais, independentemente de seu caráter erudito ou popular (Dassin, 1978 e Sandroni, 1988).

Todas estas concepções, presentes na trajetória intelectual de Mário de Andrade, foram unificadas quando da elaboração do anteprojeto do Serviço do Patrimônio Artístico Nacional (SPAN) em $1936^{8}$. Neste anteprojeto ele define como patrimônio artístico nacional "... todas as obras de arte pura ou de arte aplicada, popular ou erudita, nacional ou estrangeira..." (Andrade, 1991, p. 39). Estas obras de arte foram subdivididas em 8 (oito) categorias, a saber: arte arqueológica (1), arte ameríndia (2), arte popular (3), arte histórica (4), arte erudita nacional (5) e estrangeira (6), arte aplicada nacional (7) e estrangeira (8).

(8) Em 1934, o ministro da Educação e Saúde Gustavo Capanema solicitou a Mário de Andrade a elaboração de um anteprojeto de lei de proteção à arte no Brasil. Este encargo deveu-se sobretudo a sua posição de destaque no modernismo e do seu estreito contato com o grupo modernista mineiro. Baseado em parte neste texto de Mário de Andrade, Rodrigo Melo Franco de Andrade redigiu o DecretoLei n. 25 que deu formato legal ao SPHAN em 1937

Nestas categorias ele incorporou o que hoje se chama de bens culturais de natureza material e imaterial. Dentre os bens materiais se encontram os objetos (os móveis, as tapeçarias, a cerâmica, os instrumentos de caça, de pesca e de agricultura, etc.), os monumentos (as jazidas funerárias, a arquitetura popular, os fortes, as igrejas, etc.) e as paisagens (os aldeamentos, as grutas trabalhadas, os agrupamentos de mocambos, etc.). Já os bens imateriais são aqueles vinculados ao folclore e à cultura popular: 
os vocabulários, os cantos, as lendas, as magias, a medicina e a culinária ameríndia, a música popular, as superstições, os provérbios, as danças, etc.

Vê-se, assim, que Mário de Andrade identificou como patrimônio artístico as obras de arte erudita e popular, segundo a concepção que estava sendo desenvolvida no DC de São Paulo. Neste sentido, pode-se observar que sua definição de patrimônio artístico era mais abrangente que a comumente utilizada à época. Esta definição possuía uma base antropológica e etnológica. Somente na década de 70, com o emprego pela Unesco do conceito de patrimônio cultural $^{9}$ é que foi utilizada uma categoria de tamanha envergadura que compreendesse o universo proposto por Mário de Andrade. De fato, nos anos 40 ainda não existia um suporte conceitual capaz de dar conta da percepção que Mário possuía da questão patrimonial. Em síntese, a sua definição de patrimônio consubstancia uma idéia de identidade e memória interétnica e intersocial. O trabalho de enquadramento da memória desenvolvido por Mário de Andrade foi pluralista, ele teve a marca da heterogeneidade.

Esta não foi, entretanto, a concepção que predominou quando da criação do SPHAN. O projeto político-ideológico do EstadoNovo, de cunho autoritário e homogeneizador, impunha claros limites à adoção de uma proposta pluralista como a de Mário de Andrade. Naquele momento, as ações do Ministério da Educação e Saúde, sob o qual o SPHAN estava subordinado, voltaram-se predominantemente para a uniformização e padronização da educação e da cultura nacional, afirmando o uso da língua portuguesa e difundindo costumes e valores morais e cívicos de uma civilização branca e católica (Schwartzman, 1984).

É verdade que os intelectuais (Rodrigo Melo Franco de Andrade, Lúcio Costa, Luís Saia entre outros) responsáveis pela política de preservação tiveram uma relativa autonomia em sua gestão, frente a estas injunções político-ideológicas. No entanto, estes intelectuais tiveram uma percepção limitada dos trabalhos de Mário de Andrade e de sua concepção de patrimônio artístico nacional.

Vê-se, por exemplo, que a definição de patrimônio histórico e artístico nacional é menos ampla do aquela definida por Mário de Andrade no anteprojeto do SPAN. No Decreto-Lei n. 25, em seu 
artigo 1, tem-se expresso que:

"constitui o patrimônio histórico e artístico nacional o conjunto dos bens móveis e imóveis existentes no país e cuja conservação seja de interesse público, quer por sua vinculação a fatos memoráveis da história do Brasil, quer por seu excepcional valor arqueológico ou etnográfico, bibliográfico ou artístico",

bem como,

"equiparam-se aos bens a que se refere o presente artigo e são também sujeitos a tombamento os monumentos naturais, bem como os sítios e paisagens que importe conservar e proteger pela feição notável com que tenham sido dotados pela natureza ou agenciados pela indústria humana."

Nesta definição os bens culturais são reduzidos à feição de bens materiais (móveis ou imóveis). Cai fora toda uma gama de bens culturais imateriais, que fazem parte da definição dada por Mário de Andrade ao patrimônio artístico nacional, vinculados maioritariamente à cultura popular, à cultura negra e à cultura ameríndia.

Por outro lado, dentro do universo de bens materiais a política de tombamento do SPHAN privilegiou a seleção de bens imóveis associados aos valores históricos e, sobretudo, aos de arte erudita. A arquitetura barroca e a arquitetura vinculada ao Estado português, às classes dirigentes regionais e à igreja católica, foram o grande objeto da preocupação e interesse do grupo pioneiro modernista no SPHAN. (Milet, 1984 e Freitas, 1992)

O trabalho de enquadramento da memória nacional desenvolvido no órgão representou uma apologia aos líderes da pátria e aos fatos memoráveis da história do país. Em artigo reproduzido na Revista do Rotary Club do Rio de Janeiro, em 1964, Rodrigo Melo Franco de Andrade, diretor do SPHAN desde sua fundação, afirma:

"quanto à memória de fatos e personagens culminantes da história do Brasil, conservam-na, mais comoventemente que qualquer compêndio, o templo votivo erigido, na elevação dominante do campo das batalhas dos Guararapes, pelo comandante vitorioso das refregas finais contra o invasor estrangeiro; a lápide que recobre os despojos do bravo Estácio de Sá; a cela humilde onde expirou o padre José de Anchieta; a 
casa abrasonada em que nasceu o poeta Gregório de Matos; aquela onde morreu Castro Alves; a casa de Rui Barbosa; e tantas e tantas outras." (Andrade, 1987, p. 57)

Foi esta linha de pensamento e atuação que foi hegemônica, desde 1936 até a década de 70 , na política de preservação do patrimônio cultural brasileiro.

Nos anos 70, o CNRC foi a principal arena institucional onde se forjaram novos conceitos sobre a questão do patrimônio cultural no país. A trajetória institucional do CNRC levou, pouco a pouco, a sua aproximação com a trajetória do então IPHAN. Neste caminho, inevitavelmente, o CNRC teve que reavaliar toda uma herança institucional e intelectual da geração modernista fundadora do SPHAN. Geração que geriu a política de preservação durante mais de 30 anos e que, mesmo em seguida, manteve forte influência sobre esta política, em razão dos principais quadros dirigentes do IPHAN (Renato Soeiro, Augusto da Silva Telles entre outros), na década de 70 , terem sido formados por esta geração. Importa agora observar como se materializou esta trajetória do CNRC, tomando como ponto de referência o trabalho de sua liderança Aloísio Magalhães.

Originariamente, a criação do CNRC foi o resultado de um questionamento sobre o papel do desenho industrial na definição de uma fisionomia própria aos produtos brasileiros. Segundo depoimento de Aloísio Magalhães:

"Existe um ponto que deflagrou a criação do Centro. Foi uma pergunta que o Ministro Severo Gomes me fez a respeito do produto brasileiro. 'Por que não se reconhece o produto brasileiro? Por que ele não tem uma fisionomia própria?' Minha resposta mais imediata foi que para se criar uma fisionomia própria de uma cultura é preciso antes conhecer a realidade desta cultura em seus diversos momentos. Existem enormes inversões de conhecimento sobre uma coisa precisa, sobre um certa tecnologia, mas a compreensão de universos mais amplos está carecendo de ser feita." (Magalhães, 1985, p.109-110)

De fato, este questionamento do ministro Severo Gomes demonstra que ele estava sensível ao projeto de Aloísio Magalhães de qualificação dos indicadores culturais brasileiros, de forma que eles

\author{
Aloísio Magalhães e a \\ noção de bens \\ culturais
}


servissem como matéria-prima para definição de um desenho industrial que desse feições caracteristicamente nacionais aos produtos industriais brasileiros. Para este projeto o ministro deu todo o seu apoio político-institucional.

Contudo, dentre o elenco de questões que estiveram presentes nos debates do CNRC certamente que o tema mais importante e mais complexo, inclusive porque engloba o ponto acima citado, foi o que tratava das relações entre cultura e desenvolvimento. Este tema permeou os trabalhos de Aloísio Magalhães seja no CNRC, como também na SPHAN/Pró-Memória e na Secretaria de Cultura do MEC. Façamos uma primeira aproximação de como Aloísio situava esta questão. Para ele,

"o grande problema com que se defronta os países em desenvolvimento é o problema de absorverem tecnologia de cuja evolução não participaram. Eles a recebem como um enxerto, enquanto que, nos países onde se originaram, elas obedeceram a um processo natural e normal de evolução e de trajetória. Então, veja bem, o problema não é você querer parar com essa importação e nós virarmos uma coisa fechada e querermos reinventar a roda. Não é isso. É você não esquecer esses segmentos próprios que poderão ou não gerar formas tecnológicas novas. Ao mesmo tempo que você tenta absorver a tecnologia mais elaborada, sabendo que é adequada." (Id., ibid., p. 221-222)

Esta nova tecnologia, que é objeto de interesse de Aloísio Magalhães, é delimitada em dois campos: o da tecnologia do produto industrial e o da tecnologia da comunicação audiovisual. A sua adoção, sem um estudo de sua compatibilidade com a realidade socioeconômica dos países onde ela seria inserida, constituiria, segundo Aloísio Magalhães, um erro. Em depoimento prestado a "CPI do Patrimônio" ele define os fundamentos deste erro: “... nenhuma das formas de valorização econômica, tecnológica e mesmo científica está verdadeiramente à disposição de todos. É uma inverdade, uma balela, a transferência de tecnologia. Isto não existe. O que existe é subordinação, venda de tecnologia, de formas de fazer, que são impostas suavemente a outras nações, mas que na verdade são imensas e novas garras, vínculos de dependência tecnológica." (Brasil, Congresso Nacional, p. 13) 
A absorção de modelos de desenvolvimento tecnológico dos países capitalistas centrais, como uma face do processo de globalização mundial, reforçaria estes vínculos de dependência. No campo cultural, de acordo com Aloísio Magalhães, este processo representaria a redução das diferenças culturais entre os países, levando, no caso brasileiro, a um esmagamento dos valores culturais locais, em virtude da incorporação indiscriminada de novos componentes a nossa cultura e, conseqüentemente, da perda dos componentes culturais da nação.

A noção de países novos, de nações emergentes, está presente tanto em Mário de Andrade como em Aloísio Magalhães. Só que com conotações diferentes. Em Mário, esta noção emerge em meio a sua preocupação quanto à incorporação da produção artística brasileira à modernidade. A via desta incorporação seria a brasilidade. Através desta via o Brasil daria a sua contribuição à ordem universal. Já Aloísio Magalhães trabalha esta noção a partir de sua ênfase em relação entre os aspectos tecnológicos, econômicos e culturais no processo de desenvolvimento. Para ele, a condição de país jovem torna possível a escolha de novas opções de desenvolvimento. A cultura de países jovens, devido a sua fragilidade, estaria mais aberta à transformação ou perda de seus caracteres culturais frente a assimilação de valores culturais e tecnológicos internacionais. Todavia, ela estaria também mais aberta à inovação cultural e tecnológica, pois não estaria ainda plenamente sedimentada.

A questão que emerge, no discurso de Aloísio Magalhães, a partir desta complexa relação entre cultura e desenvolvimento, é a questão da identidade cultural da nação. "... será que a nação brasileira pretende desenvolver-se no sentido de se tornar uma Nação rica, uma Nação forte, poderosa, porém uma Nação sem caráter?" (Magalhães, 1985, p. 39). O argumento desenvolvido por Aloísio Magalhães, durante sua trajetória institucional, como resposta a esta questão, é que o desenvolvimento do país deveria ser balizado pela identificação e conhecimento dos valores culturais da nação. Com o conhecimento destes valores teríamos parâmetros para a definição de um modelo de desenvolvimento autônomo e garantiríamos a manutenção de nossa identidade nacional. Com o seu conhecimento poderíamos corrigir o processo de desenvolvimento dependente. 
Quais seriam estes componentes culturais, estes valores culturais permanentes reiterados pelo processo histórico, que poderiam apoiar o processo de desenvolvimento da nação? Eles seriam, segundo Aloísio, os bens culturais.

A noção de bens culturais é um conceito central no pensamento de Aloísio Magalhães. E, comparativamente, ela extrapola em muito a definição de patrimônio histórico e artístico nacional utilizada até então na política de preservação. Esta noção possui um sentido amplo, incorporando desde os costumes, os hábitos, as maneiras de ser até as atividades pré-industriais. Por isto mesmo, ela é marcada pelo caráter da diversidade, da heterogeneidade das manifestações culturais da estrutura social brasileira.

Este nível conceitual tem forte referência com a prática internacional de preservação dos anos 70 , materializada nas cartas e convenções da Unesco e de outras instituições internacionais vinculadas ao campo da cultura. Convenções que firmaram os conceitos de patrimônio cultural, bens culturais e naturais e os vínculos entre o tema da identidade cultural e dos processos de desenvolvimento. A importância da contribuição de Aloísio Magalhães está justamente em ter desenvolvido um corpo teórico aplicável a nossa realidade.

Assim, em sua trajetória institucional, Aloísio Magalhães constata e acentua a importância dos bens culturais, não somente enquanto indicadores de nossa identidade cultural, mas também como instrumentos de nosso processo de desenvolvimento. Ele destaca a "importância que os referentes patrimoniais terão no desenho projetivo da Nação" (Id., ibid., p. 80), devendo estes referentes serem levados em conta quando da formulação das políticas econômicas e tecnológicas. Para tanto, os bens culturais deveriam ser identificados, registrados, preservados e devolvidos à sociedade brasileira. E foi a estas tarefas que ele se dedicou em sua trajetória dentro do aparelho cultural do Estado.

As atividades do CNRC, sob sua liderança, tiveram como objetivo, "o traçado de um sistema referencial básico para a descrição e análise da dinâmica cultural brasileira, com as seguintes características essenciais:

a. adequação às condições especificas do contexto cultural do país; 
b. abrangência e flexibilidade na descrição dos fenômenos que se processam em tal contexto, e na vinculação dos mesmos às raízes culturais do Brasil;

c. explicitação do vínculo entre o embasamento cultural brasileiro e a prática das diferentes artes, ciências e tecnologias, objetivando a percepção e o estímulo, nessas áreas, de adequadas alternativas regionais" (Brasil, CNRC, Quatro anos de trabalho, p. 04)

O trabalho de mapeamento dos bens culturais desenvolvido pelo CNRC teve um caráter multiinstitucional ${ }^{10}$ e interdisciplinar, envolvendo várias áreas do conhecimento humano. $A$ adoção de metodologias e técnicas de pesquisa seguia um modelo aberto, isto é, para cada projeto desenvolvido eram definidas metodologias e técnicas específicas, de acordo com a realidade cultural estudada. O CNRC teve assim um regime de atuação livre e flexivel, estruturando-se mais em cima de projetos. Estes projetos foram integrados em quatro programas de estudo, a saber: o do conhecimento do artesanato, o dos levantamentos socioculturais, o da história da tecnologia e da ciência no Brasil e o dos levantamentos de documentação sobre o Brasil ${ }^{11}$

Estes projetos eram desenvolvidos em quatro estágios interrelacionados de atuação: o da captação do bem cultural (identificação e coleta de informações), o de memorização (análise, indexação e arquivamento), o de referência e o de devolução.

Neste contexto, as atividades do CNRC voltaram-se simultaneamente para o tempo projetivo e o tempo pretérito. Todas as atividades destes quatro estágios eram desenvolvidas em função de servir como fundamento para definição de um modelo de desenvolvimento ou em outro termo, para definição de um desenho projetivo da nação. Contudo, os indicadores culturais deste desenho projetivo constituíam-se na trajetória do processo histórico brasileiro. Eles eram, segundo Aloísio Magalhães, indicadores pretéritos. Desta forma, é neste processo histórico que eles deveriam ser captados. Portanto, para o conhecimento deste tempo pretérito voltou-se também a atenção do CNRC.

Em depoimento de Aloísio Magalhães à "CPI do Patrimônio" temos uma visão de como ele observava esta relação entre tempo -..... projetivo e tempo pretérito.
(10) Em 1976, com a assinatura de novo convênio foi alcançada a diversificação dos orgāos oficiais que patrocinavam a continuidade do CNRC. A nova base institucional de patrocinadores incorporou as seguintes instituições:

a. a SEPLAN-PR, através da Fundação Instituto de Planejamento Econômico e Social (IPEA);

b. o MEC, através do Departamento de Assuntos Culturais (DAC);

c. o MIC, através da Secretaria de Tecnologia Industrial;

d. o Minter, através de sua Secretaria Geral e. o Ministério das Relações Exteriores, através do Departamento de Cooperação Cultural, Científica e Tecnológica:

f. a Caixa Econômica Federal

. a Caixa Economica Federal;

h. a Fundaçāo Cultural do Distrito Federal.

h. a Fundaçao Cultural do Distrito Federal.

Com a assinatura de um termo aditivo ao

Banco do Brasil S. A. e o Conselho Naciona de Desenvolvimento Científico e Tecnológico (CNPq)

(11) Destes quatros programas pode-se citar, entre outros, a realizaçāo dos seguintes

projetos:
Programa de conhecimento do artesanato:

Programa de conhecimento do artesanato:
a. Projeto de pesquisa da tecelagem popular no Triângulo Mineiro.

b. Projeto de pesquisa do registro da

fabricação de cerâmica utilitária e figurativa

de Amaro, um artista da cidade de

Tracunhaém, em Pernambuco.

c. Projeto de pesquisa de registros

fotográfico e sonoro do processo de

aproveitamento de pneumáticos para a

fabricação artesanal de diversos produtos.

d. Projeto de pesquisa de mapeamento da

d. Projeto de pesquisa de mapea
atividade artesanal no Brasil.

e. Projeto de pesquisa do artesanato

e. Projeto de pesquisa do a
indigena do Centro-Oeste.

Programa de levantamento socioculturais:

a. Projeto de levantamento ecologico e

cultural das lagoas Mundaú e Manguaba.

b. Projeto de levantamento ecológico e

cultural do Complexo Industrial-Portuário de

Suape.

c. Tracunhaém - estudo socioeconômico-

cultural para a melhoria da qualidade de vida da

comunidade.

Programa da história da tecnologia e da

Programa da histori
ciência no Brasil.

a. Projeto de pesquisa sobre as industrias

a. Projeto de pesquisa sobre as indust
familiares dos imigrantes em Orleans.

b. Banana passa - estudos para uma tecnologia

altemativa.

c. Estudo multidisciplinar do cajú

Programa dos levantamentos de

documentação sobre o Brasil:

a. Projeto de levantamento sobre a

a. Projusicologia na are

b. Projeto de estudo sobre a construçäo de

b. Projeto
Brasília.

Brasília.

d. Projeto de estudo sobre o Rio de Janeiro:

condiçōes de vida na primeira república.

e. Indexação e microfilmagem da

documentaçāo em depósito no Museu do

Indio.

f. Conceituação e classificação de bem

cultural no Brasil.

g. Projeto de estudos sobre a educação e

cultura de 1922 a 1945 
"A imagem que eu utilizo é a do estilingue ou do bodoque. A pedra irá sempre mais longe quanto mais recuarmos a borracha, e é preciso que nessa busca da força energética pretérita não ocorra ruptura, e, portanto, que se conheça, num contínuo, os componentes que fazem verdadeiramente esta energia, e aí a pedra irá mais longe, aí a Nação encontrará fôlego de enveredar por um tempo novo." (Brasil, Congresso Nacional, p. 14)

Gradativamente, com o amadurecimento do conjunto de práticas e conceitos, o CNRC aproximou-se de um novo campo de pesquisa e reflexão, o campo da preservação. Isto ocorreu por volta de 1978, já ao final do governo Geisel, quando há uma crescente preocupação da liderança do CNRC com a necessidade de institucionalização da experiência, de forma que fossem assegurados recursos financeiros para a continuidade dos projetos e fosse regularizada a situação funcional do grupo de profissionais engajado no centro.

Em entrevista a Revista Manchete (16 jun. 1979), Aloísio Magalhães afirma:

"No ano passado comecei a me preocupar com a institucionalização do CNRC. O Centro de tal maneira se desenvolvera em número de colaboradores e de atividades que necessitava ser institucionalizado. Então cheguei a conclusão de que já existia um órgão oficial onde o CNRC caberia perfeitamente: o IPHAN." (Id., ibid., p.113)

A solução encontrada foi, assim, a incorporação do CNRC ao IPHAN. A escolha deu-se em função da aproximação do campo de atuação dos dois órgãos e da posição institucional do IPHAN. Este órgão era dotado de instrumentos legais que garantiam a viabilização do projeto de registro, referência e devolução dos bens culturais. Além disto, o órgão era reconhecido nacional e internacionalmente, o que conferia um alto grau de legitimidade à política lá desenvolvida.

Para consolidação desta escolha e das propostas de reformulação da política de preservação, Aloísio Magalhães buscou solidificar as bases políticas e intelectuais de apoio ao CNRC e, também, ampliá-las (ver Miceli, 1984). Neste contexto, ele desenvolveu uma reflexão sobre a trajetória institucional do IPHAN, buscando vincular, através de alguns de seus textos, o ideário patrimonialista do CNRC com a trajetória intelectual de Mário de Andrade. 
A análise sobre a experiência do IPHAN, traduz-se numa reflexão sobre a experiência do grupo pioneiro modernista, onde sempre se destaca a menção a dois personagens, Rodrigo Melo Franco de Andrade e Mário de Andrade. Esta reflexão fundamenta-se sobre quatro pontos principais: 1 - o reconhecimento da importância histórica da experiência do IPHAN; 2 - a crítica à concepção oficial dada à cultura, à memória e à identidade nacional; 3 - a releitura da proposta inicial de patrimônio artístico nacional formulada por Mário de Andrade; e, 4 - a afirmação da conformidade do pensamento de Rodrigo Melo Franco de Andrade com o pensamento de Mário de Andrade.

A trajetória institucional do IPHAN, em sua etapa inicial, era definida por Aloísio Magalhães como uma etapa inevitável e necessária:

"... Rodrigo nos primeiros tempos do Patrimônio viu, de maneira extremamente inteligente, que tinha que atacar em uma só linha, a mais drasticamente atingida. Eram os prédios. Derrubavam-se prédios históricos. O grande trabalho foi conscientizar as elites: governo, clero, poder judiciário. Essa função que era prioritária, acabou se confundindo com o IPHAN." (Id., ibid., p. 218)

A partir deste último ponto é que o grupo de intelectuais do CNRC e Aloísio Magalhães desenvolveram a sua crítica ao IPHAN. Para eles, o aspecto negativo consiste no fato que desta ação vital, dos primeiros tempos do patrimônio, o grupo pioneiro tenha reduzido a ação preservacionista ao foco dos bens monumentais do patrimônio arquitetônico. O grupo do CNRC critica, assim, a concepção oficial dada à cultura, à identidade e à memória nacional, ao afirmar a dimensão elitista do conceito de patrimônio histórico e artístico nacional (bens monumentais arquitetônicos enquanto componentes centrais da cultura nacional) e da prática de preservação. Houve, de fato, por parte de Aloísio Magalhães, um reconhecimento da importância do acúmulo de conhecimentos técnicos e metodológicos aplicados à área de conservação e do restauro dos bens móveis e imóveis. Porém, como contrapartida, houve o reconhecimento da rigidez da estrutura conceituai, administrativa e funcional do IPHAN, o que estava conduzindo inclusive a perda de todo o legado de conhecimentos deixado pela geração modernista.

Aloísio Magalhães defendeu, a partir da fusão entre o CNRC e o IPHAN, uma renovação da prática preservacionista.
Mário de Andrade em Aloísio Magalhães 
“... a aproximação que o CNRC deu ao conceito de bem cultural atinge uma área de que o patrimônio não estava cuidando. Ou seja: o bem cultural móvel, as atividades do povo, as atividades artesanais, os hábitos culturais da comunidade. $O$ patrimônio atuava de cima para baixo e, de certo modo com uma concepção principalmente elitista. A igreja e o prédio monumental são bens culturais, mas de um nível muito alto. São o resultado mais apurado da cultura. O CNRC procura trabalhar de baixo para cima. Pela própria razão de ser, uma atividade popular não tem consciência de seu valor. Quem faz uma igreja sabe o valor do que faz. Mas quem trabalha couro, por exemplo, nem sempre. Desse contraponto pode surgir uma hipótese - a de que o CNRC começava a tocar nas coisas vivas, enquanto o IPHAN se preocupava principalmente com as coisas mortas. Pelo contrário, é através das coisas vivas que se deve verificar que as do passado não devem ser tomadas como mortas. O IPHAN já estava convencido dessa necessidade de revitalizar o passado, para ele não morrer. Acho que é possivel essa síntese. Por isso acho que eu fui para lá." (Id., ibid., p.217-218)

Nesta proposta de renovação da prática preservacionista, Aloísio Magalhães também propôs que fosse dado um novo tratamento à memória; “... eu prefiro o conceito biológico de memória: guardar, reter, para em seguida mobilizar e devolver" (Id., ibid., p. 67). Frente à idéia de memória cristalizada, que tem como suporte aqueles valores mais representativos do passado histórico, ele contrapôs a idéia de memória viva, onde surgem como suporte os componentes culturais deste passado que são identificados no processo de desenvolvimento. Por isso, para ele:

"Não tem sentido a memória apenas para guardar o passado. Não tem sentido que esses documentos e bens fiquem apenas porque foram belos e foram úteis no passado. É preciso que voltem a ser úteis, é preciso que estejam a disposição do pessoal moço que precisa entender esses componentes para poder entender o que deve fazer deste país. $E$ é nesse sentido que a tarefa da preservação do patrimônio cultural brasileiro, ao invés de ser uma tarefa de cuidar do passado, é essencialmente uma tarefa de refletir sobre o futuro." (Id., ibid., p. 192)

Permeando todo este processo de incorporação do CNRC ao IPHAN, Aloísio Magalhães realizou uma aproximação de suas concepções, desenvolvidas desde meados dos anos 70, ao ideário de Mário de Andrade materializado no anteprojeto do SPAN. 
Segundo Aloísio, a amplitude de ação do trabalho do CNRC, que ele procurava implantar no IPHAN, em 1979, não seria algo novo, “... ela está implícita no documento original de Mário de Andrade. Ou seja, curiosamente, tudo isso que a gente traz agora não é novidade. $\dot{E}$ apenas, vamos dizer, a retomada no momento histórico certo de segmentos que já estavam previstos na antecipação de Mário de Andrade. Claro que ele não podia formular como hoje eu já estou podendo formular. Por exemplo, quando ele se referia a coisas feitas pelo homem brasileiro, objetos, etc., naquele momento histórico, em 1936, não era possivel precisar, como hoje se pode, que isso tem um valor econômico preponderável na criação de novas riquezas. Eu acredito que ele não pudesse, não havia condições naquele momento de isso ser visto tão explicitamente. Mas o importante é que o segmento conceitual já estava. É um grande documento de antecipação." (Id., ibid., p. 219)

Qual seria o sentido desta referência a Mário Andrade no discurso de Alóisio Magalhães? Qual o sentido desta releitura do anteprojeto do SPAN? Com o estabelecimento de vínculos entre as concepções de Aloísio Magalhães e de Mário de Andrade buscava-se fundar uma base de legitimação ao trabalho do CNRC. Porque Mário deu uma valiosa contribuição ao processo de mapeamento dos indicadores culturais nacionais. $E$ neste processo, ele, juntamente com Rodrigo Melo Franco de Andrade, foi figura de proa nos esforços de criação do SPHAN e de preservação do patrimônio cultural brasileiro.

Além disso, esta referência a Mário de Andrade servia como instrumento de diálogo com o grupo de intelectuais remanescentes no SPHAN (Renato Soeiro, Augusto da Silva Telles, etc.). Porque este grupo, sendo sucessor do grupo pioneiro modernista, não podia se contrapor às concepções de Mário de Andrade, pois Mário era Rodrigo e Rodrigo era Mário. Quando da fundação do SPHAN as suas trajetórias se confundem, elas estiveram intimamente ligadas.

Ao mesmo tempo, esta alusão diferenciava e identificava as experiências do CNRC e do IPHAN. Por um lado ela revelava os limites da política oficial de preservação. Por outro, na origem do SPHAN (anteprojeto de Mário) ela ia forjar os elementos de identidade entre as duas experiências. 
A Constituição de 1988 e a noção de patrimônio cultural brasileiro
Em síntese, com esta referência a Mário de Andrade, Aloísio Magalhães realizava um movimento de duplo sentido: de aproximação e de afastamento da prática preservacionista oficial.

Ao final dos anos 70 , já havia sido determinado definitivamente o novo modelo do sistema de preservação do patrimônio cultural no âmbito federal. Fora criado o sistema SPHAN/Pró-Memória. O SPHAN era o órgão normativo da política de preservação. Possuía uma estrutura mínima. Nele foram concentrados os poderes típicos do Estado: o poder de polícia, o tombamento, a definição dos perímetros dos sítios históricos e a fiscalização. Já a Pró-Memória era o órgão executivo, ficando responsável pela parte operacional desta política, a realização de estudos, pesquisas, projetos, etc. Tal como o CNRC a Pró-Memória possuía a agilidade operacional, típica das fundações, para captação e utilização de recursos (humanos e financeiros). Era, inclusive, idéia de Aloísio Magalhães que a Pró-Memória não tivesse uma estrutura rígida e hierarquizada, a sua intenção era que ela se estruturasse através de projetos como no CNRC.

Para que houvesse um adequado funcionamento deste sistema havia um pressuposto político: a de que o presidente da PróMemória fosse o secretário da SPHAN. Apesar do êxito da transição levada à frente por Aloísio Magalhães, a adoção desta solução significou uma concessão à estrutura anterior, em razão de seu patrimônio técnico consolidado e de seu peso junto a entidades internacionais, como, por exemplo, a Unesco. O SPHAN possuía uma trajetória institucional e técnica que não podia ser deixada para trás. O órgão se tornou, assim, enquanto história de uma geração, um objeto da preservação.

Frente a este contexto, observa-se que de fato o conjunto de concepções e a prática patrimonial defendida por Aloísio Magalhães nunca se tornou hegemônica no interior do SPHAN/ Pró-Memória. Talvez ela tenha exercido uma maior influência externamente à estrutura, na sociedade civil e nos órgãos estaduais e municipais de preservação.

Mesmo porque, com a morte prematura de Aloísio Magalhães, o pressuposto anteriormente citado foi logo rompido. $O$ grupo de intelectuais oriundos do CNRC, com suas novas lideranças, não conseguiu manter, dentro do SPHAN/Pró-Memória, a hegemonia política necessária para manutenção de sua experiência. 
Se observarmos a política de tombamento do SPHAN/PróMemória, na década de 80 , poderemos constatar que se continuou a dar uma enorme ênfase à defesa e seleção dos bens que compõem o patrimônio arquitetônico. Houve uma ampliação da base social deste patrimônio. Foram tombados bens culturais vinculados à cultura afro-brasileira, como a Serra da Barriga, local da histórica república dos Palmares, e o terreiro Casa Branca, um dos mais antigos terreiros de candomblé do país. Foram tombados bens associados à imigração alemã (Casa Presser e escola rural do professor) e à nipônica (casarão do chá). Tivemos o tombamento de exemplares vinculados à história da tecnologia no Brasil, como, por exemplo, a fábrica de vinho tinto Silva \& Cia. de João Pessoa. No entanto, esta política não foi substancialmente modificada.

Só com a Constituição de 1988 foi que as concepções patrimoniais de Aloísio Magalhães foram definitivamente consagradas. O artigo 216 desta constituição, que trata do patrimônio cultural brasileiro, representa uma síntese destas concepções. Este artigo é basicamente oriundo da Comissão Afonso Arinos. Desta comissão participaram intelectuais que tiveram um contato próximo a Aloísio Magalhães, seja via CNRC ou Pró-Memória como, por exemplo, Joaquim Falcão, Eduardo Portella, Cândido Mendes de Almeida e Cristovám Buarque.

Estes intelectuais, ao introduzirem a expressão "bens de natureza material e imaterial" no conceito de patrimônio cultural brasileiro, traduziram em termos jurídicos os ideários formulados por Mário de Andrade e Aloísio Magalhães. A definição dada a este conceito incorpora uma visão interdisciplinar, presente já no pensamento internacional, e implícita no pensamento destes dois intelectuais (onde se evidencia uma visão etnológica e antropológica do patrimônio cultural).

A institucionalização desta visão pluralista de patrimônio cultural abre a perspectiva da realização de uma nova política de preservação no país, em que se trabalhe com os diversos niveis de identidade e memória social. Para efetivação desta perspectiva, entretanto, é necessário que se rompa com antigos impasses. O principal deles é a ausência de práticas societárias no desenvolvimento desta política.

A proteção do patrimônio cultural no Brasil foi uma função e responsabilidade, até hoje, eminentemente estatal. Porém, o 
estado brasileiro nunca investiu os recursos necessários à proteção deste patrimônio.

Em suas trajetórias institucionais Mário de Andrade (DC de São Paulo) e Aloísio Magalhães (CNRC e SPHAN/Pró-Memória) haviam se preocupado com a questão da democratização cultural, em termos, ora um ora outro, da definição, do acesso e do usufruto dos bens culturais. O próprio Aloísio Magalhães havia afirmado que "a própria comunidade é a melhor guardiã de seu patrimônio" (Id., ibid. p. 184). A ausência de práticas societárias não ocorre assim pela falta de ideólogos a um novo tipo de política.

Neste momento em que temos uma considerável ampliação do acervo de bens que passam a ser objeto de interesse da política de preservação do patrimônio cultural, é necessário que associemos esta política a práticas societárias de preservação, pois as memórias e identidades sociais, que tem como suporte o patrimônio cultural brasileiro, tem a sua gênese no contínuo processo de criação e fruição dos bens de natureza material e imaterial que compõem este patrimônio.

$\begin{array}{ll}\text { Siglas } & \text { CNPq } \\ & \text { CNRC } \\ \text { DAC } \\ \text { DC de São Paulo } \\ \text { FNPM } \\ \text { IPEA } \\ \text { IPHAN } \\ \text { MEC } \\ \text { MIC } \\ \text { MINIPLAN } \\ \text { Minter } \\ \text { PCH } \\ \text { Pró-Memória } \\ \text { SEMOR } \\ \\ \text { Seplan-PR } \\ \text { SPAN } \\ \text { SPHAN }\end{array}$

STI

UnB

- Conselho Nacional de Desenvolvimento Científico e Tecnológico

- Centro Nacional de Referência Cultural

- Departamento de Assuntos Culturais

- Departamento de Cultura do Municipio de São Paulo

- Fundação Nacional Pró-Memória

- Fundação/Instituto de Planejamento Econômico-Social

- Instituto do Patrimônio Histórico e Artístico Nacional

- Ministério da Educação e Cultura

- Ministério da Indústria e Comércio

- Ministério do Planejamento e Coordenação Geral

- Ministério do Interior

- Programa de Cidades Históricas

- Fundação Nacional Pró-Memória

- Secretaria de Modernizaçāo e Reforma Administrativa do Ministério do Planejamento

- Secretaria de Planejamento da Presidência da República

- Secretaria do Patrimônio Artístico Nacional

- Secretaria do Patrimônio Histórico e Artístico Nacional (1979-81 e 1985-90)

Serviço do Patrimônio Histórico e Artístico Nacional (1937-1946)

Subsecretaria do Patrimônio Histórico e Artístico Nacional (1981-85)

- Secretaria de Tecnologia Industrial

Unesco

- Universidade de Brasília

- Organização das Naçōes Unidas para a Educação, Ciência e Cultura 
ANDRADE, Mário de. A lição do amigo: cartas de Mário de Andrade a Carlos Drummond de Andrade. Rio de Janeiro: Record, 1988.

Cartas de trabalho: correspondência com Rodrigo Mello Franco de Andrade, 1936-1945. Brasília: SPHAN/ Pró-Memória, 1981.

ANDRADE, Rodrigo M. F. de. Rodrigo e o SPHAN. Rio de Janeiro: MinC/SPHAN/Pró-Memória, 1987.

BERMAN, Marshall. Tudo que é sólido desmancha no ar: a aventura da modernidade. São Paulo: Companhia da Letras, 1986.

BRASIL. CONGRESSO NACIONAL. Constituiçāo Federal de 1988. Decreto-Lein. 25, de 30 de novembro de 1937. Brasília: Centro Gráfico do Congresso Nacional (Organiza a proteção do Patrimônio Histórico e Artístico Nacional).

CONGRESSO NACIONAL. CPI do Patrimônio. In: Diário do Congresso Nacional, seção I, ano XXXVII, suplemento ao n. 90. Brasília: 01 de julho de 1982.

BRASIL. CNRC. Quatro anos de trabalho do Centro Nacional de Referência Cultural. Brasília: Centro Gráfico do Congresso Nacional , 1979.

Bases para um trabalho sobre o artesanato brasileiro hoje. Brasília: Centro Gráfico do Congresso Nacional, s/data.

DASSIN, Joan Rosalie. Política e poesia em Mário de Andrade. Sāo Paulo: Duas Cidades, 1978.

FALCÃO, Joaquim. Governo federal e patrimônio cultural. Folha de S. Paulo, São Paulo, 24 de jun. 1990.

FREITAS, Marcelo de Brito A. P. Dos monumentos arquitetônicos aos sítios históricos urbanos: um estudo sobre a evolução do padrão de intervenção estatal nos sitios históricos no Brasil. Recife, 1992. Dissertação (Mestrado) - MDU/Universidade Federal de Pernambuco.

MAGALHĀES, Aloísio. E triunfo? A questão dos bens culturais no Brasil. Rio de Janeiro: Nova Fronteira; Brasília: Fundação Nacional Pró-Memória, 1985.

Bem cultural é fator de desenvolvimento, entrevista com Aloísio Magalhães. Boletim do IPHAN, n. 4, p. 11-12, jan./fev. 1980.

O papel do patrimônio cultural no futuro da Nação. Boletim SPHAN/Pró-Memória. Brasília, n. 17, p.13-14, mar./abr. 1982.

MICELI, Sérgio. O processo de 'construção institucional' na área cultural federal (anos 70). Estado e cultura no Brasil. São Paulo: Difel, 1984, p. 58-83.

MILET, Vera. A teimosia das pedras (um estudo sobre a preservação do patrimônio ambiental no Brasil). Recife, 1984. Dissertação (Mestrado) - MDU/Universidade Federal de Pernambuco, 1984.

MORAES, Eduardo Jardim de. Modernismo revisitado. In: Estudos Históricos, v. 1, n. 2. Rio de Janeiro: Vértice-Revista dos Tribunais, 1988, p. 220-238.

SANDRONI, Carlos. Mário contra Macunaíma: cultura e política em Mário de Andrade. São Paulo: Vértice, 1988.

SCHWARTZMAN et al. Tempos de Capanema. Rio de Janeiro: Paz e Terra; São Paulo: Edusp, 1984.

SOARES, Lélia Gontijo. Mário de Andrade e o folclore. In: Mário de Andrade e a Sociedade de Etnografia e Folclore, no Departamento de Cultura da Prefeitura o Município de São Paulo, 1936-1939. Rio de Janeiro: FUNARTE, Instituto Nacional do Folclore; São Paulo: Secretaria Municipal de Cultura, 1983, p. 07-13. 